Revista Investigaciones Turísticas, no 13, pp. 140-163

ISSN: 2174-5609

DOI. http://dx.doi.org/10.14198/INTURI2017.13.07

गJ Investigaciones

\title{
Obstáculos a la gobernanza turística en la frontera del Bajo Guadiana1
}

\author{
Javier Hernández-Ramírez \\ jhernan@us.es \\ Universidad de Sevilla
}

\section{RESUMEN}

Las investigaciones que abordan la gobernanza transfronteriza en destinos turísticos revelan que existen limitaciones objetivas para que estas experiencias se desarrollen con éxito. Este trabajo pretende ser una contribución al estudio de los factores que obstaculizan la institucionalización de la gobernanza turística en áreas fronterizas. Con este objetivo se analiza un caso concreto en la frontera entre España y Portugal trazada por el río Guadiana, que sitúa en cada orilla a las poblaciones de Alcoutim (Algarve, Portugal) y Sanlúcar de Guadiana (Andalucía, España). Son estudiadas las causas que explican la débil institucionalización de la gobernanza transfronteriza atendiendo a una combinación de factores exógenos y endógenos. Se constata que la base estructural de este fenómeno es la situación de multidependencia que relega a este espacio a una posición periférica en su contexto comarcal, ya de por sí periférico.

Palabras clave: gobernanza; frontera; asimetría; multidependencia

\footnotetext{
${ }^{1}$ Este estudio ha sido realizado en el marco del proyecto: La gestión pública del Patrimonio Etnológico (P11-HUM7377). Proyecto de Excelencia de la Junta de Andalucía de la convocatoria 2011 (modalidad Motriz) financiado por la Consejería de Economía, Innovación, Ciencia y Empleo y el Ministerio de Economía y Competitividad.
} 


\title{
Obstacles to governance of tourism on the Bajo Guadiana border
}

\begin{abstract}
Research related to cross-border governance in tourist destinations reveals that there are a series of objective limitations to the successful development of these experiences. This paper aims to contribute to the study of the factors that prevent the institutionalization of crossborder governance to promote tourism. To this end, a specific case is analyzed on the border, defined by the river Guadiana, between Spain and Portugal, and two of the populations on its opposing shores; Alcoutim (in the Algarve, Portugal) and Sanlúcar de Guadiana (in Andalusia, Spain). The causes that explain the weak institutionalisation of cross-border governance are studied, taking into account a combination of exogenous and endogenous factors. This study finds that the structural base of this phenomenon is the situation of multidependence that relegates this space to a peripheral position in its regional context, which, in itself is already peripheral.
\end{abstract}

Keywords: governance; border; asymmetry; multidependence

\section{TURISMO, GOBERNANZA Y FRONTERA}

A partir de la década de los noventa del pasado siglo se inicia una importante tradición de estudios sobre la gobernanza en relación con el turismo que tiene continuidad en la actualidad (Greenwood, 1993; Hall, 2011: 437). Desde 2006 son destacables los trabajos que analizan los procesos de institucionalización de la participación de los actores involucrados en la regulación, planificación y toma de decisiones (Dredge, 2006; Bramwell y Lane, 2011; Moscardo, 2011; Muñoz-Mazón y Velasco, 2015). La relación entre sostenibilidad y gobernanza ocupa también el interés de una serie de investigadores que interpretan que la formalización de estructuras participativas en la acción política es la vía adecuada para garantizar la continuidad del turismo en un marco de equilibrio entre las dimensiones económicas, sociales y medioambientales (Timothy, 1999: 182; Bramwell, 2011: 461; Hall, 2011: 437). Otros estudios establecen tipologías de las distintas modalidades de gobernanza (Hall, 2011: 441; Fernández Tabales et al., 2015: 177) y otros determinan criterios de medición de la buena gobernanza (Beaumont y Dredge, 2010: 10; Pulido-Fernández et al., 2014: 688).

Son más escasas y recientes las investigaciones que abordan la gobernanza en destinos turísticos transfronterizos, aunque no por ello menos notables, pues los resultados de los trabajos realizados dan luz sobre el fenómeno y permiten caracterizarlo gracias a la diversidad empírica de situaciones analizadas. No obstante, son necesarios más estudios que proporcionen información para alcanzar un mayor conocimiento de las relaciones entre turismo y colaboración transfronteriza (loannides et al., 2006: 123). En este sentido, Sofield (2006: 108) llama la atención sobre el hecho de que abundan las publicaciones centradas en el estudio de 
los procesos de integración regional en el planeta, pero escasean las que examinan la cooperación transfronteriza en el campo del turismo.

Siguiendo la estela de los primeros estudios, especialmente las aportaciones de Dallen J. Timothy $(1995,1999,2001)$, los autores coinciden en que cualquier forma de cooperación implica un ejercicio de relaciones entre organizaciones que tiene como objetivo maximizar los beneficios mutuos (Tosun et al., 2005: 7). Sin embargo, en el caso de la gobernanza transfronteriza este marco relacional resulta aún más complejo, pues intervienen sectores y entidades localizados en territorios distintos con culturas organizacionales diferentes, a veces, divergentes.

No puede olvidarse que las fronteras internacionales han funcionado históricamente como barreras a los movimientos de personas, servicios, bienes e incluso ideas. En estos escenarios, el turismo se ha configurado tradicionalmente como una actividad donde han predominado estrategias de competencia antes que de colaboración (Weidenfeld, 2013: 191). Sin embargo, en la actualidad, las funciones de las fronteras están experimentando un cambio radical provocado por una suma de factores globales combinados, tales como el crecimiento de un comercio internacional cada día más interconectado, la circulación incesante de capitales, los flujos de turistas internacionales y la emergencia de estructuras políticas supranacionales que suprimen aduanas y controles (Gelbman y Timothy, 2010: 240). Estos procesos económicos y políticos se traducen en una resignificación del hecho fronterizo, ya que algunas de las anteriores fronteras de exclusión se están transformando en fronteras de inclusión (Sofield, 2006: 108) y en destinos turísticos en los que, paradójicamente, la frontera funciona como el principal atractivo (Timothy, 2001; Prokkola, 2010; Orgaz y Moral, 2014). Todos estos cambios globales son condiciones que, en principio, deberían favorecer la institucionalización de la gobernanza transfronteriza. Sin embargo, la evidencia empírica revela que, a pesar de la formalización por todo el planeta de alianzas supranacionales y las otras dinámicas globales apuntadas, persisten resistencias culturales de carácter endógeno y obstáculos de naturaleza exógena que frenan esta integración.

Como plantean distintos autores (Martínez, 1994; Timothy, 1999; loannides et al., 2006; Lovelock y Boyd, 2006; Sofield, 2006) la intensidad de las relaciones que pueden establecerse entre poblaciones fronterizas son variables según las circunstancias. Tal como se aprecia en la Figura 1, el grado de porosidad de la frontera y de asociación varía siguiendo un continuum: en un extremo la relación sería de conflicto u hostilidad, mientras que en el otro estaríamos en una situación de máxima colaboración entre las partes interesadas que intervienen en regiones ya fusionadas. Según este modelo ideal, a medida que se avanza en el proceso de vinculación, las estructuras de gobernanza se robustecen y estabilizan. 
Figura 1. Niveles de contacto transfronterizo

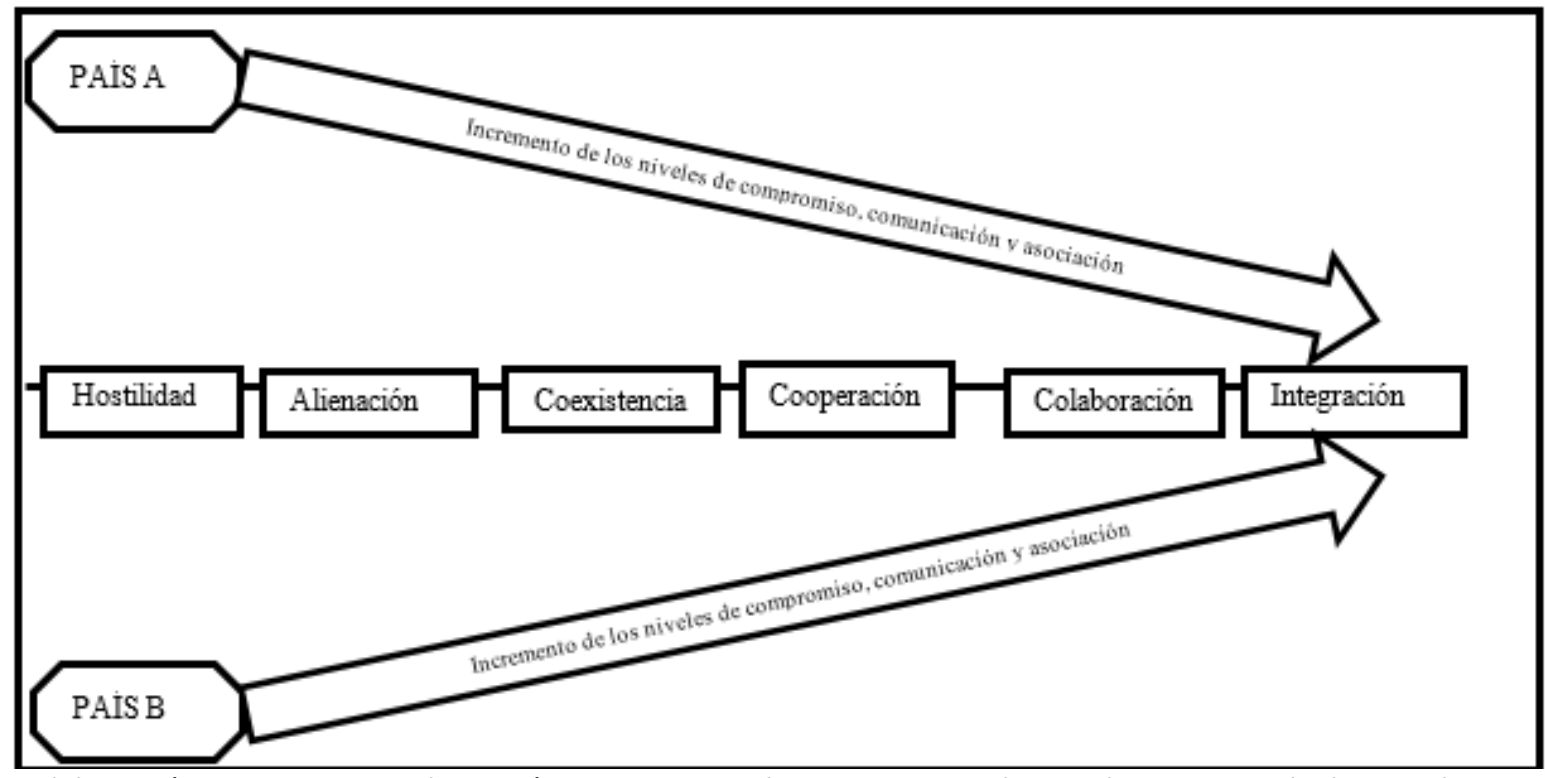

Elaboración propia a partir de Martínez 1994; Timothy, 1999; Ioannides et al., 2006; Lovelock y Boyd, 2006; Sofield, 2006.

Siguiendo el esquema precedente, una frontera hostil y en menor grado alienada la conforman territorios que son o han sido recientemente escenarios de conflictos. La tensión entre estados-nación antagónicos se materializa en férreas fronteras impermeables en las que los contactos e intercambios están muy controlados, lo que impide la formación de redes de colaboración. El siguiente nivel (coexistencia) implica el establecimiento de interacciones transfronterizas, aunque la intensidad de las mismas es mínima y la colaboración prácticamente inexistente. Esta situación se puede modificar paulatinamente a medida que los estados incrementan sus relaciones y proceden a la apertura de las fronteras. Esta nueva etapa de cooperación supone la materialización de esfuerzos iniciales entre jurisdicciones adyacentes para resolver problemas comunes y representa el primer impulso hacia una institucionalización de la gobernanza todavía frágil. La cuarta fase de colaboración se desarrolla preferentemente en un contexto de estabilidad política que facilita la materialización de iniciativas de vinculación institucionalizadas bajo sistemas de gobernanza plurales e inclusivos, capaces de integrar y articular a todos los sectores y sensibilidades de ambos lados de la frontera. El modelo ideal concluye en un marco de integración en el que todos los obstáculos fronterizos han sido erradicados, generando regiones funcionalmente fusionadas donde cada entidad renuncia voluntariamente a su soberanía para alcanzar un progreso mutuo.

Es a partir del cuarto nivel (cooperación) cuando se dan las condiciones para que emerja un sistema de gobernanza. Como se mostrará en este estudio, el caso analizado se sitúa en un estado inicial dentro de este nivel de contacto transfronterizo. 


\section{GOBERNANZA TRANSFRONTERIZA. EL ESTADO DE LA CUESTIÓN EN LAS CIENCIAS SOCIALES}

Cualquier modalidad de gobernanza es una forma de relación multisectorial institucionalizada. Pero en el marco de las relaciones transfronterizas plantea una serie de problemas específicos, por cuanto implica la institucionalización de relaciones con el objetivo de alcanzar formas de interdependencia entre entidades históricamente segregadas procedentes de ámbitos nacionales distintos. A las dificultades propias de la asociación de diferentes sectores sociales con intereses disímiles e incluso contrapuestos, aquí se une la negociación multilateral entre gobiernos, estructuras administrativas, asociaciones y grupos de interés paralelos con tradiciones, capacidades, atribuciones e incluso presupuestos generalmente asimétricos. Esta colaboración, que se desarrolla en distintos niveles (supranacionales, estatales, regionales, locales), implica asumir una estrategia conjunta de integración, cuyo camino es difícil de recorrer pues supone la cesión de autonomía y la renuncia a ciertas competencias en aras de objetivos comunes y compartidos.

Algunas investigaciones resaltan los beneficios sociales, económicos y medioambientales derivados del desarrollo de estructuras de gobernanza transfronteriza, asegurando que la cooperación puede servir para reducir las diferencias que presentan estas zonas periféricas con respecto a los principales centros metropolitanos, al tiempo que para alcanzar una posición económica más competitiva (Tosun et al., 2005: 7; Hartmann, 2006: 31; Vodeb, 2010: 220). Dentro de este campo unos autores analizan experiencias de éxito de gobernanza transfronteriza, determinando los factores que han permitido su materialización efectiva y estableciendo recomendaciones para el fomento de estrategias de cooperación (Vodeb, 2010; Blasco et al., 2014). Otros subrayan que la colaboración es más eficiente que la competencia, especialmente cuando los destinos situados a cada lado de la frontera se posicionan en el mercado con ofertas complementarias. De acuerdo con este enfoque, la colaboración entre las partes tiene como recompensa generar sinergias de todo tipo cuyo efecto combinado es superior a la suma de las partes. Paralelamente, constituye una estrategia para el control autóctono de la actividad turística, porque incrementa la capacidad de negociación local frente a sectores externos, especialmente los grandes operadores turísticos (Tosun et al., 2005: 8).

En un sentido distinto se desarrolla una literatura que constata que estas dinámicas están plagadas de tensiones que restringen considerablemente el proceso de institucionalización de redes de buena gobernanza plurales e inclusivas capaces de articular el hecho fronterizo (Bufon, 2003; loannides et al., 2006; Lovelock y Boyd, 2006; Ilbery y Saxena, 2011). Esta producción científica destaca cuatro obstáculos fundamentales. En primer lugar, las dificultades y resistencias de las administraciones para adaptarse a un marco institucional transfronterizo, pues las mismas fueron concebidas originalmente desde una lógica nacional, cuyo campo de intervención se ha centrado tradicionalmente en circunscripciones específicas (nacionales, regionales, comarcales y locales) dentro del territorio del estado. Su transformación en órganos transfronterizos puede interpretarse en el interior de estas organizaciones como una cesión de soberanía. Este nuevo reto que se pone encima de la mesa explica que, a menudo, sea la propia actitud de las administraciones situadas en cada lado de la frontera el 
principal factor que obstaculiza la formalización de estructuras transfronterizas de cooperación. En este sentido, el rechazo a una remodelación organizativa de gran calado que no se desea asumir, la carencia de experiencia en el establecimiento de redes de cooperación (Tosun et al., 2005: 16), los recelos larvados históricamente entre las partes (Lovelock y Boyd, 2006: 154; Ilberry y Saxena, 2011: 1140), la desconfianza ante los verdaderos objetivos que se esconden tras las manifestaciones de colaboración o las restricciones formales e informales aplicadas por el personal de frontera al libre tránsito de turistas (Timothy y Tosun, 2003: 419) son algunos de los factores apuntados que impiden avanzar y profundizar hacia una efectiva cooperación.

Un segundo factor es la asimetría entre las instituciones públicas (Fernández-Sánchez, 2008) y las organizaciones empresariales y civiles que operan a ambos lados de la frontera (Ilberry y Saxena, 2011). Este fenómeno se verifica a distintas escalas. A nivel nacional se comprueba que en los estados fronterizos con distintas formas de organización territorial (centralismo vs federalismo, por ejemplo) la cooperación entre las instituciones públicas con atribuciones en materia turística es compleja y está llena de tensiones. En los niveles regional y local, la asimetría se manifiesta en la falta de correspondencia entre las estructuras orgánicas, competencias y presupuestos de las instituciones circunscritas en cada territorio. Este desajuste limita la capacidad de los aparatos administrativos para conformar una estructura participativa paralela e igualitaria, pues unos disponen de más recursos y capacidad de decisión política, que sus potenciales contrapartes.

Esta divergencia se suele producir también en el ámbito empresarial y social, pues las entidades representativas de los grupos de interés (empresarial, profesional, ecologista, patrimonialista, etc.) pueden estar más desarrolladas y vertebradas en un lugar y, por el contrario, ser muy débiles en el otro. En estas situaciones de asimetría multidimensional (Ilberry y Saxena, 2011: 1141) la formalización de estructuras de gobernanza paritarias encuentra un obstáculo casi insalvable cuando la frontera ha actuado históricamente como un factor constitutivo de la identidad étnica de las poblaciones, que se refuerza por factores diversos como el uso de distintos idiomas y tradiciones de negocio (Matthiesen y Burkner, 2001: 43; loannides et al., 2006: 131). En estos contextos es difícil invertir la tendencia a la competencia entre los actores (loannides et al., 2006: 136), especialmente cuando, además, existe escasa diferenciación entre los productos ofertados (Ioannides et al., 2006: 136).

El tercer factor de bloqueo se deriva de la tensión y competencia entre los intereses de las administraciones generales del estado y las situadas en un nivel inferior en la frontera (loannides, et al., 2006: 136). Por último, un cuarto elemento negativo a la gobernanza puede ser la intervención de organismos supranacionales que financian proyectos y crean nuevas entidades transfronterizas (público-privadas y organismos públicos), generando escenarios de decisión paralelos. Estas nuevas estructuras pueden suscitar conflictos y resistencias en el interior de las estructuras de poder tradicionales y una fuerte competencia entre las entidades de cada estado por la captación de las subvenciones procedentes de la administración superior.

La suma de este conjunto de factores se traduce al final en una débil colaboración intersectorial, una relación de competencia estructural e incluso el fracaso del proceso de integración. En esta investigación se constata que en la unidad de observación seleccionada 
concurren esos factores de bloqueo al desarrollo de estructuras participativas de gobernanza transfronteriza.

\section{METODOLOGÍA Y SELECCIÓN DE LAS UNIDADES DE INFORMACIÓN}

En este estudio se toman como referentes empíricos las localidades vecinas de Alcoutim y Sanlúcar de Guadiana que se sitúan en la frontera entre la región del Algarve (Portugal) y la Comunidad Autónoma de Andalucía (España). La investigación se ha basado en un trabajo de campo desarrollado in situ desde octubre de 2015 hasta julio de 2016, aplicando dos técnicas de investigación propias de la antropología social: observación directa y participante de la realidad cotidiana y entrevistas en profundidad dirigidas a informantes cualificados. Como se indica en la Tabla 1, se han entrevistado once informantes privilegiados que ocupan cargos de responsabilidad en los ámbitos locales de decisión política, el sector empresarial vinculado con el turismo y el entramado asociativo.

Tabla 1. Perfil de los actores sociales entrevistados

\begin{tabular}{|c|c|l|}
\hline Ámbito & Institución y entidad & \multicolumn{1}{|c|}{ Cargo } \\
\hline \multirow{4}{*}{ Espacio Político } & Municipios & Alcalde \\
\cline { 2 - 3 } & & Concejal de gobierno \\
\cline { 2 - 3 } & & Líder de la oposición \\
\cline { 2 - 3 } Espacio económico & & Concejal de la oposición \\
\cline { 2 - 3 } & & Responsable técnico de Turismo \\
\cline { 2 - 3 } & Establecimientos Hosteleros & Empresario \\
\hline \multirow{3}{*}{ Espacio asociativo } & Establecimientos Hoteleros & Empresario \\
\cline { 2 - 3 } & Asociación Transfronteriza Alcoutim-Sanlúcar & Directivo \\
\cline { 2 - 3 } & Hermandad de Ntra. Sra. de La Rábida & Hermano Mayor \\
\cline { 2 - 3 } & Asociación de Mujeres y Escuela de Adultos & Representante \\
\hline
\end{tabular}

En la siguiente tabla, se indican los sectores clave en la gobernanza de base local transfronteriza, lo que revela la representatividad de la muestra seleccionada. 
Tabla 2. Sectores clave en la gobernanza de base local transfronteriza

\begin{tabular}{|c|c|c|}
\hline Ámbito institucional & Instituciones y entidades & Actores \\
\hline \multirow[t]{2}{*}{ Espacio político } & Ayuntamiento de Sanlúcar de Guadiana & \multirow[t]{2}{*}{$\begin{array}{l}\text {-Responsables de Partidos de gobierno } \\
\text {-Responsables de Grupos de la oposición } \\
\text {-Responsables y técnicos del sector turístico }\end{array}$} \\
\hline & Cámara Municipal de Alcoutim & \\
\hline \multirow[b]{3}{*}{ Espacio económico ${ }^{2}$} & Empresas del subsector hostelero & -Empresarios de Bares y restaurantes \\
\hline & Empresas del subsector hotelero & -Empresarios de Hoteles y albergues \\
\hline & Empresas del subsector de turismo activo & $\begin{array}{l}\text {-Responsables de empresas de Navegación, } \\
\text { actividades náuticas y senderismo }\end{array}$ \\
\hline \multirow{4}{*}{ Espacio asociativo } & Entidades transfronterizas & \multirow{4}{*}{-Directivos y socios } \\
\hline & Clubes deportivos & \\
\hline & $\begin{array}{l}\text { Asociaciones de mujeres, tercera edad, } \\
\text { juveniles y escolares }\end{array}$ & \\
\hline & Entidades socio-ceremoniales y culturales & \\
\hline
\end{tabular}

Como puede apreciarse en la Tabla 3, los temas tratados en las entrevistas abiertas han versado sobre el perfil y trayectoria de los propios actores y las entidades que representan, así como por valoraciones sobre los distintos niveles de administración pública, las relaciones transfronterizas, el grado de gobernanza alcanzado, la evolución de la actividad turística y las perspectivas de futuro.

Tabla 3. Temáticas planteadas en las entrevistas abiertas dirigidas a líderes políticos, empresarios y directivos de entidades

\begin{tabular}{|c|c|}
\hline Cuestiones fundamentales & Cuestiones específicas \\
\hline Identificación del informante & $\begin{array}{l}\text {-Nombre, edad, lugar de nacimiento. } \\
\text {-Experiencia profesional. } \\
\text {-Trayectoria como responsable político, empresarial y/o de entidad. } \\
\text {-Descripción, evolución y peso específico del grupo político, asociación o } \\
\text { empresa que lidera dentro del territorio transfronterizo. }\end{array}$ \\
\hline $\begin{array}{l}\text { Descripción y valoración de la } \\
\text { realidad social de su localidad }\end{array}$ & $\begin{array}{l}\text {-Caracterización demográfica. } \\
\text {-Bases económicas y sector turístico. } \\
\text {-Patrimonio cultural. } \\
\text {-Sociabilidad, asociacionismo, eventos y rituales. } \\
\text {-Valoración de la política local. }\end{array}$ \\
\hline $\begin{array}{l}\text { Gobernanza turística: ámbito } \\
\text { político }\end{array}$ & $\begin{array}{l}\text {-Identificación de los organismos, asociaciones o entidades supralocales en } \\
\text { los que se integra la administración local. } \\
\text {-Determinación del tipo de participación de la administración local en } \\
\text { instituciones públicas supralocales. } \\
\text {-Valoración del papel de las distintas administraciones (Comunitarias, }\end{array}$ \\
\hline
\end{tabular}

${ }^{2}$ En 2016 la oferta hotelera suma en torno a las doscientas plazas (48 en Sanlúcar y 148 en Alcoutim) en forma de casas rurales, pensiones y albergues. La oferta gastronómica está más desarrollada en Alcoutim, donde los seis restaurantes existentes gozan de un relativo prestigio, mientras que en Sanlúcar este tipo de negocio está todavía escasamente desarrollado en número (4 establecimientos) y en calidad del servicio. Por último, en ambas localidades operan cinco de empresas de turismo activo, las cuales aprovechan el Guadiana como su principal recurso. 


\begin{tabular}{|c|c|}
\hline & $\begin{array}{l}\text { nacionales, regionales y locales) en el diseño y aplicación de una estrategia } \\
\text { conjunta de desarrollo. } \\
\text {-Valoración de las instituciones públicas supralocales en cuanto a } \\
\text { organización y logros. }\end{array}$ \\
\hline $\begin{array}{l}\text { Gobernanza turística: ámbito } \\
\text { empresarial }\end{array}$ & $\begin{array}{l}\text {-Identificación de las empresas con mayor iniciativa y participación en el } \\
\text { terreno turístico. } \\
\text {-Determinación del papel de las empresas turísticas en la planificación y } \\
\text { toma de decisiones. } \\
\text {-Valoración del rol del sector turístico en la gobernanza transfronteriza }\end{array}$ \\
\hline $\begin{array}{l}\text { Gobernanza turística: ámbito } \\
\text { social }\end{array}$ & $\begin{array}{l}\text { - Identificación de las entidades y personalidades con mayor iniciativa y } \\
\text { participación en el terreno turístico. } \\
\text {-Determinación de la intervención de la sociedad civil en la planificación y } \\
\text { toma de decisiones en materia turística. } \\
\text {-Valoración del papel de las entidades transfronterizas en la gobernanza } \\
\text { turística. }\end{array}$ \\
\hline $\begin{array}{l}\text { Descripción y valoración de las } \\
\text { relaciones transfronterizas }\end{array}$ & $\begin{array}{l}\text {-Memoria de la frontera y de las relaciones transfronterizas (parentesco, } \\
\text { comercio, rituales, controles y aperturas...). } \\
\text {-Comparación de las relaciones transfronterizas en el proceso histórico. } \\
\text {-Valoración de los principales obstáculos respecto de la institucionalización } \\
\text { de un sistema de gobernanza transfronterizo inclusivo y participativo. }\end{array}$ \\
\hline
\end{tabular}

Una serie de estancias cortas y regulares en las sociedades de estudio ha permitido contrastar las informaciones aportadas por los informantes entrevistados y obtener un conocimiento profundo de las realidades locales (bases económicas, sociabilidad, asociacionismo, organizaciones e instituciones políticas locales, ciclo festivo-ceremonial, patrimonio cultural, relaciones transfronterizas y actividad turística). En este sentido, se han efectuado numerosos contactos informales con el vecindario, asistido a rituales festivos, participado en encuentros ciudadanos, al tiempo que visitado espacios productivos y lugares de la sociabilidad de ambos pueblos. Esta información cualitativa se ha complementado con el análisis de la producción bibliográfica sobre gobernanza y turismo transfronterizo, así como con el estudio de la documentación producida por las instituciones públicas lusas e hispanas sobre la unidad de observación.

\section{UNA FRONTERA PERIFÉRICA Y MULTIDEPENDIENTE}

Sanlúcar y Alcoutim son poblaciones que se emplazan una frente a la otra separadas tan solo por el cauce del río Guadiana que, en este punto, delimita la frontera. Esta corta distancia se hace más apreciable por la horizontalidad del paisaje fluvial que permite contemplar con nitidez el caserío colindante e incluso ver (y reconocer en el caso de los nativos) a los vecinos del otro lado cuando se acercan a los embarcaderos o pantalanes de su orilla. 
Mapa 1. Detalle del mapa del ámbito transfronterizo del Bajo Guadiana

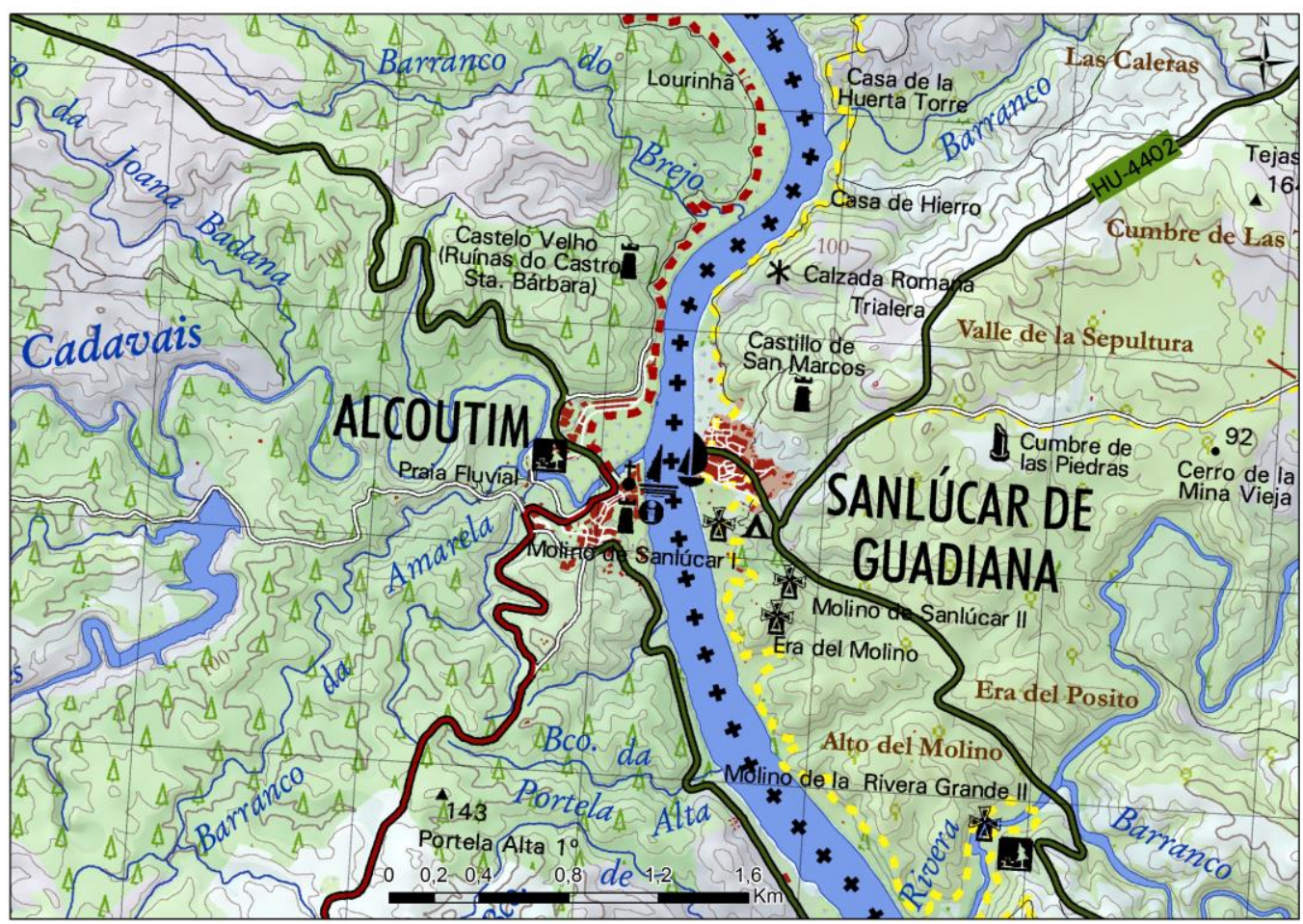

Escala 1:50.000. Instituto de Estadística y Cartografía de Andalucía y Direçâo-Geral do Territorio, Instituto Geográfico Nacional 2013.

Ambos municipios se integran en la llamada Raya ibérica; un vasto territorio definido por una frontera de $1.292 \mathrm{kms}$. (Campesino y Jurado, 2014) que, en su diversidad, experimenta dos tendencias paralelas. Una primera regresiva, derivada del acelerado despoblamiento, envejecimiento, declive de las actividades tradicionales, desarticulación territorial interna y creciente periferización (Márquez, Gordo y Jurado, 2012; Campesino, 2013; Covas y Tão, 2013; Domínguez, 2013; Felicidades, 2012; Márquez 2013 y 2014; Padín 2013; Senabre, 2013; Jurado y Pazos, 2016). Este conjunto de factores constituye un obstáculo objetivo al desarrollo (Márquez, Gordo y Jurado, 2012) que no ha sido invertido a pesar de las políticas de desfronterización (Lois y Cairo, 2011) o desactivación de la frontera impulsadas por organismos supranacionales tales como la Eurorregión Alentejo-Algarve-Andalucía (Márquez, 2012; Felicidades, 2012), la cual interviene en el ámbito territorial donde se emplazan las unidades de observación seleccionadas para este estudio (Márquez, 2012).

La otra tendencia es dinámica. Tiene que ver sobre todo con un desarrollo turístico, en general incipiente, pero que paulatinamente se posiciona como uno de los sectores económicos más pujantes, debido a la puesta en valor de multiplicidad de recursos naturales y bienes patrimoniales (Hortelano, 2015). Dada la riqueza natural y cultural de este territorio fronterizo, las perspectivas de desarrollo turístico futuro son interesantes y prometedoras, pues gran parte de estos bienes y paisajes patrimoniales abundantes y de calidad son todavía recursos "potenciales con atractivos y rentabilidad expectante" que no han sido transformados en productos turísticos (Campesino, 2016: 67), por lo que son múltiples los retos y oportunidades 
derivados de la actividad turística, especialmente en zonas concretas como las que se analizan en este trabajo (Felicidades, 2012: 562). Esta orientación estratégica y productiva podría, potencialmente, revertir o minimizar los efectos negativos de dinámicas regresivas como la despoblación, siempre que su desarrollo se oriente hacia la preservación, recuperación y revalorización del patrimonio natural y cultural y a la mejora de las condiciones de vida de las poblaciones autóctonas (Jurado y Pazos, 2016: 270).

Siendo esto así, la oferta turística tomada en su conjunto es en toda la zona rayana diversificada y creciente. En el amplio abanico existente, caben resaltar distintas modalidades asociadas al ecoturismo (geoturismo, turismo ornitológico, avistamento de fauna...), turismo cultural (turismo enogastronómico, peregrinaciones, rituales, fiestas, patrimonio histórico...) o turismo activo (senderismo, cicloturismo, multiaventura...) (Hortelano, 2015: 259). En algunos tramos de la raya bañados por ríos, lagos y embalses, el turismo fluvial es un sugestivo y destacado producto (Campesino, 2016). Precisamente esta última tipología es el segmento principal de los municipios objeto de este estudio, dado que el Guadiana es navegable hasta los pequeños puertos deportivos de Alcoutim y Sanlúcar. A este atractivo se suma el hecho de que el cauce del río marca la frontera entre España y Portugal, lo que propicia el desarrollo de un turismo de frontera (Felicidades, 2012: 543; Jurado, 2014). El desarrollo actual y la potencialidad de este conjunto de recursos son factores que contribuyen a que esta raya húmeda bañada por el Guadiana (junto con la otra raya húmeda del Miño) sea uno de los territorios más dinámicos de esta frontera ibérica (Lois y Carballo, 2015: 203) aunque con importantes desequilibrios entre la zona litoral, especializada en el turismo de sol y playa, y la de interior, orientada hacia el rural, que es la que se analizará en este trabajo (Márquez, 2010 y 2012).

Sanlúcar de Guadiana y Alcoutim forman parte del territorio transfronterizo denominado Bajo Guadiana y se integran en la Eurorregión Alentejo-Algarve-Andalucía. Dentro de sus respectivos estados, Sanlúcar de Guadiana se sitúa en el Andévalo y Alcoutim en la Sierra del Algarve. Ambas comarcas naturales se encuentran entre las más deprimidas en términos demográficos y socio-económicos de Andalucía y el Algarve. En este contexto territorial, las localidades objeto de estudio se localizan muy alejadas de los principales centros de actividad económica y de decisión política de sus regiones (Andalucía y Algarve). En otras palabras, constituyen un espacio periférico dentro de comarcas ya de por sí periféricas. 
Mapa 2. Localización de la región transfronteriza del Bajo Guadiana

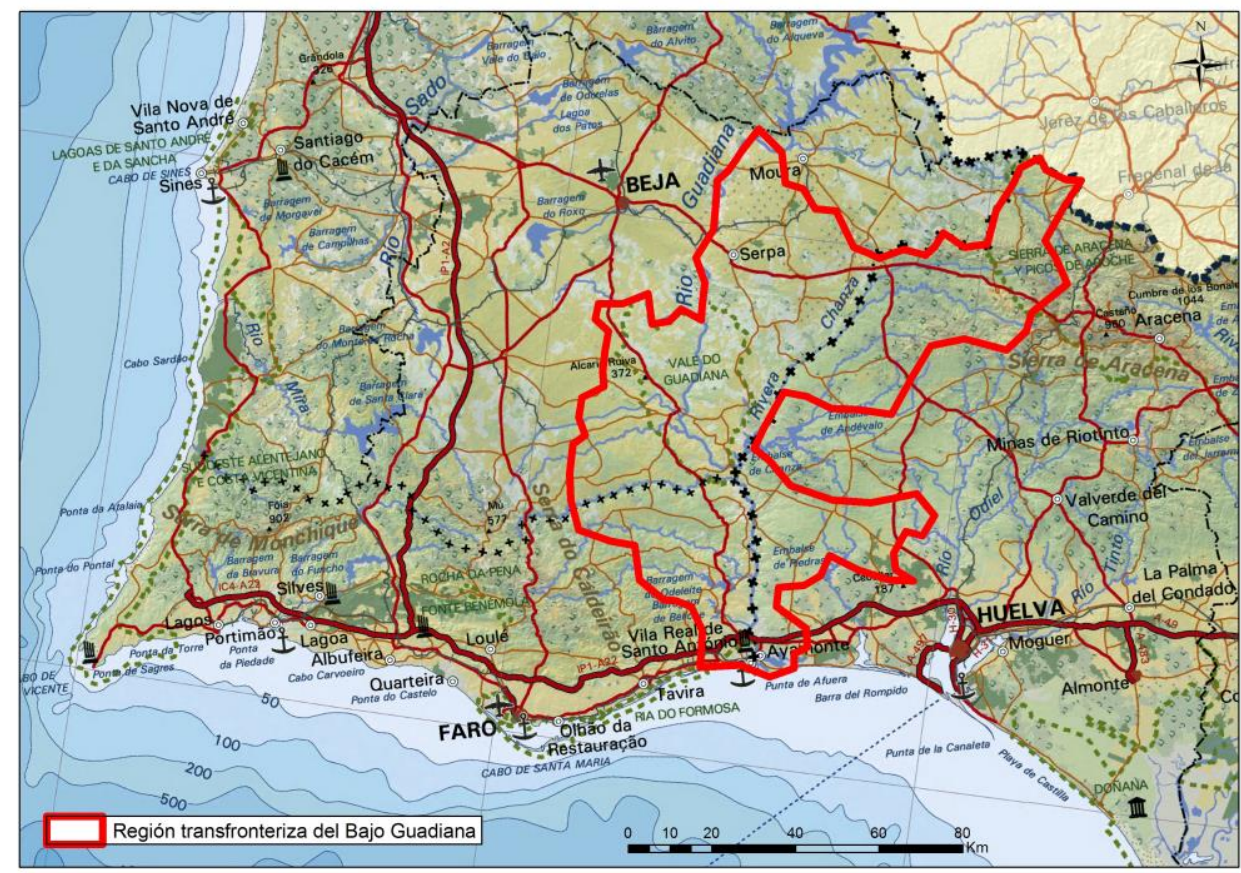

Fuente: Consejería de Medio Ambiente y Ordenación del Territorio. Junta de Andalucía.

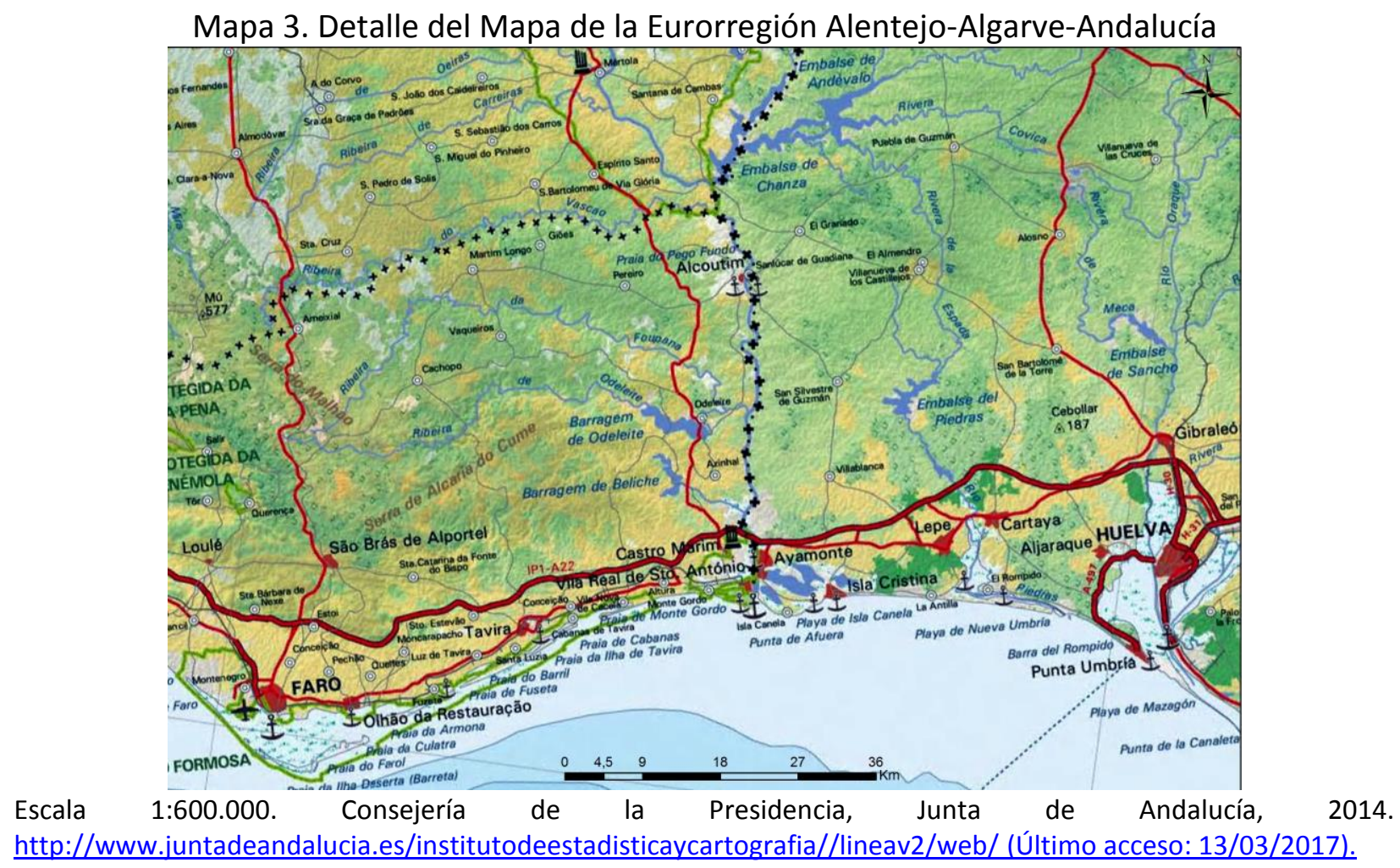

Investigaciones Turísticas

$N^{\circ} 13$, enero-junio 2017, pp. 140-163 
Alcoutim y Sanlúcar de Guadiana son un ejemplo paradigmático de lo que Hall (2005: 246-247) denominó peripheral border areas, es decir, de zonas que ocupan una posición multiperiférica, lo que las convierte en sociedades con escasa capacidad endógena para invertir una situación de dependencia que puede terminar siendo estructural e irreversible. Por un lado, son sociedades demográficamente regresivas y geográficamente alejadas de los principales centros productivos y los circuitos de mercado, lo que dificulta su desarrollo y su vinculación con otras áreas. Al mismo tiempo desempeñan un rol institucional marginal en el contexto político, lo que se traduce en una muy limitada capacidad para el ejercicio de un efectivo control político y económico sobre las decisiones más importantes en relación con su desarrollo. Como señalan Ilberry et al. (2011: 1151) la posición multiperiférica es uno de los obstáculos más evidentes para el desarrollo de la gobernanza. Esta hipótesis se constata también en este estudio.

No obstante, del mismo modo que ocurre en otras zonas fronterizas, la posición marginal con respecto a los principales centros productivos y los lugares de decisión política ha permitido mantener espacios de alto valor ecológico y patrimonial, lo que potencialmente puede servir de base para el desarrollo turístico (loannides et al., 2006: 128) ${ }^{3}$. En el caso que nos ocupa el propio hecho fronterizo podría funcionar como un poderoso reclamo turístico, lo cual ha sido analizado anteriormente en otras zonas (Timothy, 2001; Gelbman y Timothy, 2010; Orgaz y Moral, 2014).

La condición de espacio de frontera con interesantes valores ecológicos y la cercanía del litoral algaravío y onubense convierten a este paisaje cultural en un escenario atractivo para diversidad de turistas nacionales e internacionales, que están transformando paulatinamente a ambos municipios en destinos turísticos emergentes (Jurado, 2014). Sin embargo, esta potencialidad no ha derivado todavía en formas cooperativas de gestión transfronteriza vinculantes entre las poblaciones de las dos orillas.

El objetivo de este estudio es el análisis de las dinámicas que bloquean la cooperación entre los sectores de ambos lados de la frontera atendiendo al grado de interconexión y colaboración existente entre los niveles supranacional, nacional, regional, interlocal y local. En la investigación se verifica cómo los beneficios potenciales que pueden derivarse de la creación de un espacio transfronterizo colaborativo quedan neutralizados por las correspondientes prioridades e intereses que nacen de los distintos ámbitos, por la profunda desarticulación que existe entre todos estos niveles y por el predominio de un sistema "top/down" en el proceso de toma de decisiones que rara vez se vincula con las aspiraciones populares. De acuerdo con este enfoque, en las siguientes páginas se analizan los distintos niveles que intervienen en la construcción de este espacio turístico transfronterizo.

\footnotetext{
${ }^{3}$ Las márgenes del río Guadiana son espacios protegidos integrados en la Red Natura 2000. La ribera andaluza se incluye en la Lista de Lugares de Importancia Comunitaria (LIC) y ha sido declarada Zona Especial de Conservación (ZEC). La margen portuguesa está dentro del Parque Natural Vale do Guadiana y el 50\% de la superficie del Concelho de Alcoutim forma parte de un área de Reserva Ecológica Nacional (REN). Asimismo, los bienes culturales más emblemáticos de ambas localidades se integran en los catálogos patrimoniales de sus respectivos países. 


\section{EL NIVEL SUPRANACIONAL}

Desde 1989 la CEE (y a partir de 1993 la UE) promueve iniciativas financiadas por los Fondos de Desarrollo Regional que se enfocan en gran medida hacia la cooperación trasnacional, constituyendo el fomento del turismo transfronterizo uno de sus ejes más destacados (Faby, 2006; Nilsson et al., 2010; Hortelano, 2013; Pereira y Pereiro, 2014). La frontera del Bajo Guadiana también se ha beneficiado de estas ayudas con la ejecución de programas que, de acuerdo con una serie de directrices diseñadas y fijadas desde Bruselas, se materializan en proyectos concretos (Felicidades, 2012; Márquez, Gordo y Jurado, 2012; Márquez, 2012) ${ }^{4}$.

La integración en la UE supone la transferencia de competencias y de poder desde los estados y regiones hacia la nueva estructura supranacional. Este recorte de atribuciones se trata de superar incorporando como gestores de los proyectos a administraciones y entidades de desarrollo localizadas en los territorios donde se ubican (gobiernos regionales, diputaciones, mancomunidades y asociaciones para el desarrollo). Sin embargo, el diseño de las intervenciones se realiza desde Bruselas en el marco de estrategias generales que persiguen la integración europea. Es decir, las directrices vienen marcadas desde arriba en un modelo "top/down" en el que es limitada la capacidad de los actores situados en escalones inferiores para adaptar las propuestas a las realidades y necesidades concretas de la zona.

El caso que nos ocupa deja ver que el balance de la política de ayudas promovidas por la UE ha propiciado tres dinámicas fundamentales que no contribuyen a la gobernanza turística transfronteriza.

La primera de ellas consiste en la paradoja que suponen las propias ayudas, las cuales han sido pensadas para promover la integración, pero generan un contexto contradictorio con este propósito, porque a veces propician la competencia y la desconexión antes que la cooperación entre ambos lados de la frontera. El marco es, por tanto, de relativa rivalidad entre las administraciones y las entidades de desarrollo, las cuales tratan de convertirse en las beneficiarias de los proyectos, lo que les permite controlar las ayudas públicas. En otras palabras, cuando estas instituciones compiten por participar como líderes de los proyectos de cooperación promovidos por la UE lo suelen hacer porque ven en ellos una oportunidad práctica para financiar determinadas actuaciones en su circunscripción antes que como un paso hacia la cooperación transfronteriza. En esta situación, advertida en otro contexto por llberry y Saxena (2011: 1141-1142), la competencia por el control de los fondos origina, además, desconfianza entre los potenciales socios.

La segunda dinámica se deriva del gasto superfluo que suponen algunas de las inversiones de la Unión Europea. En este sentido, los proyectos europeos son muchas veces percibidos como erráticos por no ajustarse a las demandas de la población y diseñarse desde centros de decisión muy alejados de esta periférica frontera. Los propios informantes no dudan en calificar la política de la UE como de despilfarro, pues consideran que son inversiones

\footnotetext{
${ }^{4}$ Estos proyectos se han integrado en sucesivos programas dentro del marco general de la Política de Cohesión: INTERREG I (1989-93), INTERREG II (1994-99), INTERREG III (2000-06) y POCTEP (2007-13).
} 
inadecuadas y de escasa rentabilidad social y económica. En el trabajo de campo se ha podido observar que gran parte de este dinero público se destina a equipamientos culturales, especialmente centros de interpretación y ferias (de tradiciones, gastronómicas, musicales, etc.) que proliferan y se replican por todo el territorio, generando escenarios clónicos que son poco atractivos para el posible visitante. También se financian restauraciones de bienes culturales inmuebles, que se acompañan de todo tipo de instalaciones (paneles, señalética, senderos, espacios expositivos...), cuyo mantenimiento se convierte en una herencia costosa para estos pequeños ayuntamientos, los cuales disponen de escasos recursos dados sus esqueléticos presupuestos. El resultado es que, generalmente, dichos equipamientos públicos terminan siendo infrautilizados, alcanzando pasados unos pocos años un deterioro acelerado. Del mismo modo, los eventos apenas tienen continuidad cuando cesan las ayudas exteriores.

La tercera dinámica que bloquea la gobernanza tiene que ver con las instituciones transfronterizas creadas por la UE para canalizar las ayudas. Estas estructuras tienen escaso eco e incluso son desconocidas entre los sectores afectados más directamente. Por su mayor peso destaca la Eurorregión Alentejo-Algarve-Andalucía que fue creada en 2010 con el objetivo específico de formalizar una estructura de cooperación regional que integre a las tres grandes unidades administrativas del sur de España y Portugal. Sin embargo, aunque los documentos y declaraciones públicas abundan en afirmaciones sobre la necesaria cooperación y la conformación de una estructura de gobernanza que incluya a todos los sectores de la sociedad pertenecientes a ambas nacionalidades, la etnografía realizada revela que en las unidades de observación existe un desconocimiento profundo sobre la propia existencia de esta entidad administrativa transfronteriza. Ni siquiera sus políticos están bien informados de las funciones y competencias de la Eurorregión, porque no participan directamente en unas superestructuras en las que tan solo operan políticos, funcionarios y técnicos de las administraciones regionales y provinciales.

En definitiva, las iniciativas supranacionales no se articulan correctamente con los ámbitos inferiores, generando dinámicas que no favorecen la cooperación transfronteriza, sino que incrementan la competencia. Con la entrada en la UE, los centros de decisión política más influyentes se han alejado y distanciado aún más de las poblaciones locales, incapaces de influir sobre sus destinos, lo que ha acentuado el carácter multidependiente de estos territorios.

\section{LOS NIVELES NACIONAL, REGIONAL Y COMARCAL}

En estos niveles se han identificado tres factores clave que neutralizan el avance de la gobernanza transfronteriza en la zona de estudio. El primero es la formalización o consolidación de estructuras administrativas cuyo ámbito de actuación se circunscribe al territorio nacional, las cuales articulan a los pueblos en sus correspondientes comarcas, provincias y regiones. Este fenómeno, que se produce en paralelo con el proceso de integración europea, genera tanto en España como en Portugal otras dinámicas menos llamativas pero más trascendentales en la configuración territorial. En el ámbito de estudio la consolidación de la autonomía andaluza, la creación de la Comisión de Coordinación y Desarrollo Regional del Algarve (CCDR), el reforzamiento de la Diputación Provincial de Huelva y la constitución de la Mancomunidad de 
Municipios Beturia han fomentado políticas que se centran en los territorios que administran, lo que no favorece la emergencia de un sistema de gobernanza entre ambos países. En este sentido, la institucionalización de estas estructuras administrativas ajustadas a territorios nacionales produce "desestructuración de todo el área fronteriza" (Hernández, et al. 1999: 50).

Este es el contexto que ayuda a explicar por qué en las dos últimas décadas, a pesar de la apertura de la frontera, Sanlúcar de Guadiana y Alcoutim se han distanciado más que acercado. Ambos municipios encuadran sus actuaciones en el marco de los proyectos que lideran estas instituciones, las cuales facilitan además recursos muy necesarios e irrenunciables y promueven una serie de instrumentos de planificación centrados en sus territorios. El resultado de todo ello es que las comarcas fronterizas de todo el Bajo Guadiana viven de espaldas, ignorándose y sin coordinación. Prácticamente, no existe una planificación ambiental, turística, territorial compartida, ni proyectos transfronterizos vinculantes. Aunque los documentos públicos insisten en la necesidad de impulsar la cooperación, "cada parte actúa como si el territorio no tuviera continuidad al otro lado de la frontera [...] Se carece de una visión conjunta de la realidad territorial, la frontera funciona como límite del vacío" (Hildebrand, 2012: 5).

El segundo factor que dificulta la cooperación es la asimetría institucional. Entre ambos países el marco legal, el sistema administrativo de la planificación y la organización territorial son muy diferentes. En el nivel regional la asimetría es evidente. España es un estado descentralizado en autonomías y Portugal es un ejemplo de centralización. En el caso portugués, las regiones son entidades puramente administrativas (Fernández-Sánchez, 2008; Felicidades, 2012). La Comisión de Coordinación y Desarrollo Regional del Algarve (CCDR) es un organismo periférico que depende de la lejana Lisboa y dispone de escasas atribuciones si se compara con la Comunidad Autónoma de Andalucía. Y en el plano comarcal y local ocurre lo mismo pero en sentido inverso, ya que en Portugal el poder de los municipios es mucho mayor que en España (Fernández-Sánchez, 2008; Felicidades, 2012). Esto se aprecia con nitidez en la zona estudiada, pues el municipio de Sanlúcar de Guadiana apenas tiene atribuciones específicas y depende de la Diputación Provincial de Huelva o de la Mancomunidad de Municipios Beturia, lo que contrasta con el Concelho de Alcoutim, el cual cuenta con mayores competencias, albergando la sede de entidades receptoras de fondos europeos 5 . En definitiva, en el plano regional y comarcal no existen administraciones paralelas que permitan negociar en pie de igualdad el sistema de gobernanza transfronterizo con compromisos vinculantes $y$ paritarios para la planificación y la toma de decisiones.

El tercer factor de bloqueo es el predominio de una cultura organizacional localista excesivamente apegada a determinados hábitos y formas de funcionamiento instalados históricamente en cada territorio. Esto se manifiesta de distintas maneras. En primer lugar en el sentido de que existe escasa voluntad de cooperar con sus potenciales contrapartes que se perciben antes como competidores por la obtención de ayudas de la UE que como colaboradores. A ello se suma, en segundo lugar, que el elevado número de entidades y autoridades con competencias en el espacio transfronterizo suelen desarrollar visiones

\footnotetext{
${ }^{5}$ Destaca la Associação para o Desenvolvimento do Baixo Guadiana (ODIANA) fundada en 1998 por los municipios de Alcoutim, Castro Marim y Vila Real de Santo António.
} 
estratégicas y territoriales diferentes e incluso divergentes. Todo ello se acentúa por la labor de los técnicos y funcionarios empleados en estos organismos territorialmente fijos que terminan desarrollando actitudes encerradas en el propio lado de la frontera y que contemplan como una amenaza a su estabilidad profesional cualquier modificación trasnacional de sus estructuras administrativas. En definitiva, como ocurre en otras zonas, el enfoque nosotros vs ellos está incrustado en las estructuras administrativas (Blasco et al., 2014: 161).

\section{EL NIVEL INTERLOCAL}

La frontera que marca el Guadiana no es un espacio en disputa ni una barrera infranqueable, especialmente tras la integración de ambos países en la CEE en 1986. Es, además, un entorno con una gran potencialidad turística. Sin embargo, en el nivel interlocal no ha cristalizado una estructura de gobernanza estable ni se han formalizado alianzas sustanciales entre las poblaciones de ambas orillas.

Siguiendo el modelo propuesto (Figura 1), las relaciones transfronterizas son aquí de cooperación, pero en un nivel muy limitado. Los contactos son poco frecuentes y de escasa incidencia social y económica, y los niveles de interacción producidos entre los responsables políticos, los sectores empresariales y las personas que participan en entidades sociales son mínimos. De hecho, hasta ahora no ha madurado ninguna de las escasas iniciativas de colaboración planteadas en los últimos años.

La situación es llamativa, porque la apertura de la frontera entre ambos países supuso la abolición de todos los controles aduaneros. Después de muchos años de cierre férreo, los vecinos de Alcoutim y Sanlúcar de Guadiana podían cruzar libremente el río. Sin embargo, paradójicamente, los contactos entre ellos se han reducido sustancialmente. Con la frontera cerrada a cal y canto en tiempos de las dictaduras de Salazar y Franco, las relaciones vecinales fronterizas estaban muy vigiladas. Guardia Civil a un lado y Guardia Fiscal al otro impedían el libre tráfico de mercancías y personas. Estos controles se atenuaban cuando se celebraban las fiestas en cada una de las localidades. En este tiempo extraordinario alcoutenejos y sanluqueños cruzaban el río para acercarse a los mercados improvisados para la ocasión donde adquirían productos que escaseaban en su país o cuyo precio era muy inferior. La oportunidad de comprar verdaderas gangas era la base del éxito de las fiestas. Como resultado de estos contactos esporádicos y muy controlados, los vecinos de ambos lados chapurreaban el idioma vecino y establecían relaciones comerciales y amistosas.

Es paradójico comprobar que la apertura de la frontera no se tradujo, como podría creerse a primera vista, en una intensificación de los contactos, sino todo lo contrario. Las causas son complejas: de un lado, la globalización se ha traducido en la homogeneización y pérdida de singularidad de los mercados, lo que hace casi siempre innecesario desplazarse al otro lado de la frontera para comprar; de otro, el desarrollo de estructuras políticas que intervienen en circunscripciones situadas en el interior de cada estado. Obviamente, ambas circunstancias no favorecen tampoco el desarrollo de asociaciones transfronterizas ni avanzar en la cooperación entre las administraciones locales.

En esta frontera no existe ninguna entidad transfronteriza de carácter interlocal y han fracasado todas las iniciativas en este sentido. El caso más interesante fue el de la Asociación 
Transfronteriza Alcoutim-Sanlúcar (ATAS) que desde el año 2000 promovió distintas actividades y proyectos de vinculación. Sin embargo, la dificultad para encontrar apoyo público más allá del municipio y la dependencia con respecto a las corporaciones locales respectivas, se tradujo en un paulatino desgaste de la entidad que terminó disolviéndose en 2011.

En el plano político interlocal la cooperación entre ambas partes se limita hoy a negociaciones muy concretas especialmente sobre la gestión del río (puertos, embarcaciones, navegación) sin desarrollarse ningún organismo compartido. Esto se debe a cuatro factores fundamentales: en primer lugar, a la asimetría institucional ya referida; en segundo, a las limitaciones objetivas (legales y jurídicas) que tienen las autoridades locales para actuar fuera de sus jurisdicciones sin la autorización de entidades supralocales; en tercer lugar, a la inestabilidad de las relaciones entre las corporaciones, sujetas a periodos de rivalidad y colaboración dependiendo del color político de los partidos que ocupan alternativamente el poder local; y, por último, al localismo y la falta de confianza entre los políticos y actores de ambas fronteras.

Como resultado de todo lo anterior, las dos sociedades viven ajenas y desarrollan caminos separados. Aun cuando existen relaciones históricas reforzadas a través de rituales tradicionales en los que participan vecinos de ambas comunidades y sus responsables políticos y sociales, los contactos son generalmente escasos, predominando la indiferencia, el desconocimiento y la ignorancia. Da la impresión de que, para las sociedades locales, el río funciona como una frontera infranqueable; un Finisterre tras el cual sólo existe el vacío.

\section{EL NIVEL LOCAL}

A pesar de su cercanía, ambas sociedades son muy distintas en los planos político y asociativo. En el político, Alcoutim cuenta con mayores recursos y, sobre todo, de autonomía, actuando como un interlocutor directo con el gobierno central, mientras que la corporación local de Sanlúcar de Guadiana es un eslabón débil en la estructura administrativa, que apenas tiene capacidad fuera de las directrices marcadas por entidades mayores. De este modo explicaba un responsable político sanluqueño la percepción de las autoridades de Alcoutim con respecto a su pueblo: "ellos son casi como una Diputación Provincial, por eso nos miran como si fuéramos una simple freguesia"6. Esta perspectiva está bastante generalizada en la localidad y no carece de fundamento, pues en los proyectos de desarrollo impulsados por Bruselas, Alcoutim figura explícitamente como socio, junto con otras Cámaras municipales portuguesas del Bajo Guadiana, mientras que Sanlúcar de Guadiana no aparece como tal, pues queda subsumida en la Diputación de Huelva o la Mancomunidad de Municipios Beturia. Obviamente, esta asimetría limita la formalización de acuerdos compartidos. A esta circunstancia desfavorable se une otro factor en el que sí coinciden las dos poblaciones: la fuerte polarización política interna, la cual dificulta el proceso de toma de decisiones y neutraliza los avances realizados por una corporación cuando en otra legislatura el grupo opositor accede al poder.

${ }^{6}$ Freguesia es la denominación que en los países de habla lusa se da a las entidades menores (con límites territoriales definidos) en las que se divide cada municipio o concelho.

Investigaciones Turísticas

$\mathrm{N}^{\circ} 13$, enero-junio 2017, pp. 140-163 
En cuanto al tejido asociativo ambas sociedades coinciden en la debilidad, por cuanto no existen organizaciones críticas y propositivas que calen en cada comunidad. En Sanlúcar el asociacionismo es muy frágil, ya que la única entidad que posee capacidad integradora (Hermandad patronal de Nuestra Señora de la Rábida) no interviene directamente en el desarrollo turístico y las restantes organizaciones tienen escasa afiliación y, generalmente, una existencia efímera. Por su parte, en Alcoutim el asociacionismo está más asentado, sin embargo, las entidades están estrechamente vinculadas a la Cámara Municipal de la que dependen en cuanto a su financiación, por lo que su funcionamiento suele estar muy condicionado. Esta debilidad estructural de la sociedad civil es un factor clave que explica la inexistencia de una organización empresarial transfronteriza y de un asociacionismo reflexivo que sensibilice a las poblaciones sobre los valores ecológicos y patrimoniales de la frontera.

En definitiva, un conjunto de factores locales sitúa a este espacio periférico en una posición de multidependencia, constituyendo obstáculos objetivos a la gobernanza transfronteriza. Son los siguientes: la crisis estructural de las bases económicas, el declive demográfico y el carácter envejecido de la población, la escasa capacidad de la política municipal para impulsar autónomamente proyectos de futuro, la ausencia de un asociacionismo crítico y la incapacidad de las propias sociedades para financiar directamente proyectos de desarrollo, porque dependen de fondos externos.

En este contexto regresivo, tanto los responsables públicos como los empresarios contemplan el sector turístico como la panacea que puede invertir esta condición de multidependencia. En las entrevistas, los responsables públicos y sociales coinciden en considerar que, ante la carencia de recursos económicos y la limitada capacidad de maniobra de las administraciones locales, es necesario impulsar la privatización y ampliación de las instalaciones portuarias y, en general, desarrollar estrategias conducentes a la atracción de inversores externos que impulsen planes de desarrollo turístico. En esta lógica, una serie de megaproyectos ideados y promovidos por capital externo (pendientes de su materialización) son generalmente bien recibidos por las autoridades locales, las cuales están dispuestas a facilitar su ejecución adaptando en la medida de sus posibilidades la planificación territorial, pues los contemplan como la única alternativa para generar empleo y salir de una dinámica de estancamiento socioeconómico estructural. Sin embargo, estas iniciativas son de alto riesgo por cuanto persiguen replicar un modelo agresivo con el medio ambiente y el patrimonio cultural que ha sido implantado en las últimas décadas en el litoral andaluz y algaravío. La ausencia de voces críticas, articuladas en organizaciones de corte social, ecologista y patrimonialista, favorece la consolidación de esta ideología que considera la penetración de capital externo como la única receta posible. 


\section{CONCLUSIONES}

En este estudio se han analizado las dinámicas que bloquean la cooperación transfronteriza y la institucionalización de un sistema de gobernanza turística. La investigación ha revelado la necesidad de integrar en el análisis distintos niveles territoriales e institucionales, atendiendo tanto a factores exógenos como endógenos y considerando la interconexión existente entre las dimensiones macro y micro. En el caso de estudio se aprecia una profunda desvertebración entre todos estos niveles y una escasa capacidad de los actores locales para determinar autónomamente su estrategia de desarrollo turístico. Estos problemas se agravan aquí porque las unidades de observación se sitúan lejos de los centros de decisión política.

De forma sintética puede afirmarse que la posición de multidependencia de este espacio periférico con respecto a otras zonas es la base estructural que explica las dificultades objetivas para formalizar una colaboración transfronteriza institucionalizada en forma de gobernanza. El caso estudiado muestra que queda aún mucho camino por recorrer para la formalización de un sistema de gobernanza efectivo. Siguiendo el modelo ideal propuesto (Figura 1), podría señalarse que Alcoutim y Sanlúcar de Guadiana se sitúan en un nivel transfronterizo de relaciones de "cooperación", porque existen las bases para el arranque de un proceso de convergencia. Sin embargo, aunque ha sido abolida la frontera y los intercambios no sufren ya los controles aduaneros de antaño, esta conexión aún se encuentra en un estado embrionario por la muy limitada capacidad de integración de los actores de ambos lados de la frontera.

Aunque el empoderamiento local que se produce con la efectiva institucionalización de sistemas de gobernanza no tiene porqué traer consigo una automática superación de las dificultades que impiden alcanzar el éxito de las políticas turísticas, es obvio que en el caso estudiado la consolidación de un sistema de Buena Gobernanza es la vía más adecuada para crear un nuevo escenario capaz de articular a los actores involucrados en objetivos de interés colectivo, bajo fórmulas de coordinación y compromiso participativas, eficaces y transparentes $y$, al mismo tiempo, generar valiosas sinergias que sitúen al destino en una posición ventajosa en el mercado turístico.

En el Bajo Guadiana esta cooperación podría favorecer el ejercicio de un control autóctono de la actividad orientado hacia el mantenimiento de una realidad turística, todavía emergente, basada en el aprovechamiento sostenible de los recursos culturales y naturales del entorno. Solo de este modo se está en condiciones de negociar con sectores externos, especialmente con los grandes operadores turísticos animados por el desarrollo de un modelo depredador que se basa en la explotación intensiva de los recursos y que coloca a los objetivos de la industria por encima de las necesidades locales. Ante este desafío, la gobernanza se convierte en un instrumento de las personas para que en sus entornos sociales puedan gestionar en común sus bienes colectivos y su futuro. 


\section{REFERENCIAS BIBLIOGRAFICAS}

Beaumont, N. y Dredge, D. (2010). Local tourism governance: a comparison of three network approaches. Journal of Sustainable Tourism, 18(1), 7-28.

Blasco, D., Guia, J. y Prats, L. (2014). Emergence of governance in cross-border destinations. Annals of Tourism Research, 49, 159-173.

Bramwell, B. (2011). Governance, the state and sustainable tourism: a political economy approach. Journal of Sustainable Tourism, 19(4-5), 459-477.

Bramwell, B. y Lane, B. (2011). Critical research on the governance of tourism and sustainability. Journal of Sustainable Tourism, 19(4-5), 411-421.

Bufon, M. (2003). Cross-border cooperation in the Upper Adriatic. En J. Anderson, L. O'Dowd, T. M. Wilson, (Eds.). New borders for a changing Europe: Cross-border cooperation and governance (pp. 177-196). London: Portland.

Campesino Fernández, A-J. (2013). Caracterización territorial de la frontera de Extremadura. En A-J. Campesino (Dir.). Turismo de Frontera I, (pp. 9-26). RIET. Rede Ibérica de Entidades Transfronteiriças.

Campesino Fernández, A-J. (2016). Paisajes del agua y turismo fluvial en la Raya ibérica. En J. F. Vera, J. Olcina y Ma Hernández (eds.) Paisaje, cultura territorial y vivencia de la geografía. Libro homenaje al profesor Alfredo Morales Gil, (pp. 47-72). Alicante: Universidad de Alicante.

Campesino Fernández, A-J. y Jurado Almonte, J. M. (Dirs.) (2014). Turismo de Frontera III. Productos turísticos de la Raya Ibérica. Huelva: Universidad de Huelva.

Covas, A. y Tão, M. (2013). Caracterização Socioeconómica da Região de Fronteira AlgarveHuelva. En L. Domínguez (Coord.). Estudio socioeconómico de la frontera entre Portugal y España, (pp. 385-457). Salamanca: RIET. Rede Ibérica de Entidades Transfronteiriças.

Dredge, D. (2006). Networks, conflict and collaborative communities. Journal of Sustainable Tourism, 14(6), 562-581.

Domínguez Castro, Luis (Coord.). (2013). Estudio socioeconómico de la frontera entre Portugal y España. Salamanca: RIET. Rede Ibérica de Entidades Transfronteiriças.

Faby, H. (2006). Tourism policy tools applied by the European Union to support cross-bordered tourism. En H. Wachowiak (Ed.). Tourism and border: Contemporary issues, policies and international research (pp. 19-30). Aldershot, England: Ashgate.

Felicidades García, J. (2012). Bases territoriales para la construcción regional en el espacio fronterizo del Suroeste peninsular. Tesis Doctoral. Huelva: Universidad de Huelva.

Fernández-Sánchez, P. A. (2008). La asimetría institucional entre España y Portugal en el marco de la cooperación transfronteriza (Andalucía, Algarve y Alentejo). Barcelona: Atelier Libros.

Fernández Tabales, A., Mercado, I. y Villar, A. (2015). Gobernanza territorial y gestión de espacios turísticos en contextos de fuerte presión inmobiliaria. Análisis de buenas prácticas locales en la costa de Cádiz (España). Revista de Geografía Norte Grande. Pontificia Universidad Católica de Chile, 60, 173-194.

Gelbman, A. y Timothy, D. J. (2010). From hostile boundaries to tourist attractions. Current Issues in Tourism, 13(3), 239-259.

Greenwood, J. (1993). Business interest groups in tourism governance. Tourism Management, $14,335-348$. 
Hall, C. M. (2005). Tourism: Rethinking the social Science of mobility. London, Pearson educational.

Hall, C. M. (2011). A typology of governance and its implications for tourism policy analysis. Journal of Sustainable Tourism, 19(4-5), 437-457.

Hartmann, K. (2006). Destination management in cross-border regions. En H. Wachowiak (Ed.). Tourism and borders: Contemporary issues, policies and international research (pp. 89-109). Aldershot, England: Ashgate.

Hernández, E., Castaño, Á., Quintero, V. y Cáceres, R. (1999). Fiesta y Frontera. Transformaciones de las expresiones simbólicas en la franja fronteriza de Huelva. Sevilla: Junta de Andalucía.

Hildebrand, A. (2012). La cooperación transfronteriza entre Andalucía-Algarve-Alentejo en el proyecto Andalbagua (POCTEP 2007-2013). El reto de lograr un desarrollo territorial coherente a ambos lados de la frontera. Ponferrada: Ponencia en Primer Congreso Territorial del Noroeste Ibérico. http://congresonoroiberico.com/documentos/20121107\%20\%20ANDREAS\%20HILDENBRAND\%20-\%20ponencia.pdf (último acceso: 13/03/2017).

Hortelano, L. A. (2013). El turismo de la Raya ibérica en la cooperación transfronteriza de primera generación (1992-2013): el caso de Castilla y León”. En A-J. Campesino (Dir.). Turismo de Frontera I, (pp. 129-139). RIET. Rede Ibérica de Entidades Transfronteiriças.

Hortelano, L. A. (2015). El Patrimonio territorial como activo turístico en la «raya» de Castilla y León con Portugal. Cuadernos de Turismo, 36, 247-268.

Ilbery, B. y Saxena, G. (2011). Integrated rural tourism in the English-Welsh cross-border region: an analysis of strategic, administrative and personal challenges. Regional Studies, vol. 45(8), 1139-1155.

loannides, D., Nielsen, P. A., Billing, P. (2006). Transboundary collaboration in tourism: The case of the Bothnian Arc. Tourism Geographic: An international Journal of Tourism Space, Place and Environment, 8(2), 122-142.

Jurado Almonte, J. M. (2014). El turismo de frontera en la provincia de Huelva, de la potencialidad de sus recursos a destino y producto turístico. En A.-J. Campesino y J. M. Jurado (Dir.) Turismo de frontera III: productos turísticos de la raya ibérica (pp. 113-134). Huelva: Universidad de Huelva.

Jurado Almonte, J. M. y Pazos García, F. J. (2016). Población y turismo rural en territorios de baja densidad demográfica en España. Boletín de la Asociación de Geógrafos españoles, 71, 247272.

Lois, M. y Cairo, H. (2011). Desfronterización y refronterización en la Península Ibérica, Geopolítica(s), 2 (1), 11-22.

Lois, R. C. y Carballo, A. C. (2015). La frontera hispano-lusa en la actualidad: una visión geográfica. Revista de historiografía, 23, 191-214.

Lovelock, B. y Boyd, S. (2006). Impediments to a cross-border collaborative model of destination management in the Catlins, New Zealand. Tourism Geographic: An international Journal of Tourism Space, Place and Environment, 8(2), 143-161. 
Márquez Domínguez, J. A. (2010). Deconstrucción y articulación territorial de la frontera lusoandaluza. Cuadernos Geográficos, 47, 297-316.

Márquez Domínguez, J. A. (2012). Desactivación de la frontera. Desvertebración de la Raya lusoandaluza y desenfoque de las políticas territoriales de desarrollo. Saarbrüken (Alemania): Editorial Académica Española.

Márquez Domínguez, J. A. (2013). El territorio de la frontera en la región del Algarve, el distrito del Baixo Alentejo y la provincia de Huelva. En A-J. Campesino Fernández (Dir.), Turismo de Frontera I, (27-35). RIET. Rede Ibérica de Entidades Transfronteiriças.

Márquez Domínguez, J. A. (2014). Desarrollo difícil y turismo en la frontera Portugal-España. En A-J. Campesino y J. M. Jurado (Dirs.). Turismo de Frontera (III). Productos turísticos en la Raya ibérica, (pp. 199-220). Huelva: Servicio de publicaciones, Universidad de Huelva.

Márquez Domínguez, J. A. (Dir.) Gordo Márquez, M. y Jurado Almonte J. M. (Coord.) (2012). Desarrollo en la frontera del Bajo Guadiana. Documentos para la cooperación lusoandaluza. Huelva: Servicio de publicaciones, Universidad de Huelva.

Martinez, O. (1994). The dynamics of border interaction: New approaches to border analysis. En C. H. Schofield (Ed.) World boundaries Vol. 1: Global boundaries (pp. 1-15). London, Routledge.

Matthiesen, U. y Burkner, H. J. (2001). Antagonistic structures in border areas: Local milieux and local politics in the Polish-German twin city Gubin/Guben. GeoJournal, 54(1), 43-50.

Moscardo, G. (2011). Exploring social representations of tourism planning: issues of governance. Journal of Sustainable Tourism, 19(4-5), 423-436.

Muñoz-Mazón, A. y Velasco, M. (2015). Colaboración y gobernanza para el desarrollo turístico. Aranjuez como estudio de caso. Cuadernos de Turismo, 35, 311-334.

Nilsson, J., Eskilsson, L. y Ek, R. (2010). Creating cross-border destinations: Interreg programmes and regionalization in the Baltic sea area. Scandinavian Journal of Hospitality and Tourism, 10(2) 153-172.

Orgaz, F. y Moral, S. (2014). El mercado binacional como recurso turístico en la frontera dominico-haitiana. Un análisis cuantitativo. Investigaciones turísticas, 8, 46-62.

Padín Fabeiro, C. (2013). Aproximación a la caracterización territorial de la Raya Ibérica: Galicia. En A.-J. Campesino (Dir.), Turismo de Frontera I, (pp. 51-58). RIET. Rede Ibérica de Entidades Transfronteiriças.

Pereira, V. y Pereiro, X. (2014). Turismo transfronteiriço na Euro-região Galiza-Norte de Portugal. Revista Turismo e Desenvolvimento, 21-22(2), 285-294.

Prokkola, E-K. (2010). Borders in tourism: the transformation of the Swedish-Finnish border landscape. Current Issues in Tourism, 13(3), 223-238.

Pulido-Fernández, M. C. y Pulido-Fernández, J. I. (2014). ¿Existe la gobernanza en la actual gestión de los destinos turísticos? Estudio de casos. Pasos. Revista de Turismo y Patrimonio Cultural, 12(4), 685-705.

Senabre, D. (2013). Caracterización territorial de la Raya Ibérica. El ámbito de la frontera entre Portugal y España. Castilla y León. En A-J. Campesino (Dir.), Turismo de Frontera I, (37-50). RIET. Rede Ibérica de Entidades Transfronteiriças.

Sofield, T. (2006). Border tourism and border communities: An overview. Tourism Geographies: An International Journal of Tourism Space, Place and Environment, 8(2), 102-121. 
Timothy, D. J. (1995). Political boundaries and tourism: borders as tourist attractions. Tourism Management, 16 (7), 525-532.

Timothy, D. J. (1999). Cross-border partnership in tourism resource management: international parks along the US-Canada border. Journal of Sustainable Tourism, 7(3-4), 182-205.

Timothy, D. J. (2001). Tourism and political boundaries. New York, Routledge.

Timothy, D. J. y Tosun, C. (2003). Tourists' perceptions of the Canada-USA border as a barrier to tourism at the International Peace Garden. Tourism Management, 24, 411-421.

Tosun, C., Timothy, D. J., Parpairis, A. y Macdonald, D. (2005). Cross-border cooperation in tourism marketing growth strategies. Journal of Travel and Tourism Marketing, 18 (1), 5-23.

Vodeb, K. (2010). Cross-border regions as potential tourist destinations along the sloven and croatian frontier. Tourism and Hospitality Management, 16(2), 219-228.

Weidenfeld, A. (2013). Tourism and cross border regional innovation systems. Annals of Tourism Research, 42, 191-213.

\section{Listado de mapas}

Mapa 1. Detalle del Mapa del ámbito transfronterizo del Bajo Guadiana. Escala 1:50.000. Instituto de Estadística y Cartografía de Andalucía y Direçâo-Geral do Territorio, Instituto Geográfico Nacional 2013.

Mapa 2. Localización de la región transfronteriza del Bajo Guadiana. Fuente: Consejería de Medio Ambiente y Ordenación del Territorio. Junta de Andalucía.

Mapa 3. Detalle del Mapa de la Eurorregión Alentejo-Algarve-Andalucía. Escala 1:600.000. Consejería de la Presidencia, Junta de Andalucía, 2014.

\section{Listado de Figuras y Tablas}

Figura 1. Niveles de contacto transfronterizo.

Tabla 1. Perfil de los actores sociales entrevistados

Tabla 2. Sectores clave en la gobernanza de base local transfronteriza

Tabla 3. Temáticas planteadas en las entrevistas dirigidas a líderes políticos, empresarios y directivos de entidades

Para citar este artículo: Hernández Ramírez, J. (2017). Obstáculos a la gobernanza turística en la frontera del Bajo Guadiana. Investigaciones Turísticas, (13), 140-163. http://dx.doi.org/10.461/INTURI2017.13.07 